\title{
Analysis of Outsourcing Activities in the Banking Industry in Nigeria: The Rationale and Perceived Benefits
}

\author{
Bolanle Mistura Sanusi \\ Department of Business Administration, Osun State University, Okuku Campus, Osun State, Nigeria
}

\begin{abstract}
This study examined rationale and benefits for outsourcing in Nigerian banking industry. The study utilized primary data which were collected through questionnaire and key informant interviews. The data collected were analysed using descriptive and inferential statistical techniques. The paper found that security, cleaning, recruitment, training, human resources and ATM are the most outsourced services in the Nigerian Banking Industry. The study however revealed that, technical convenience and efficiency, increased productivity/performance, the need to focus on core activities, Improvement of service delivery and quality, as well as to meet changing customers' needs are the major rationale for outsourcing in Nigerian banking industry. In addition, the study concluded that increased flexibility, growth of banks and increased services are the major benefits of outsourcing in the Nigerian Banking Industry. The study however concluded that, poor suppliers' problem, reputation damage and poor expertise delivery are the major risk which the banking industry are confronted with whenever they outsource their activities.
\end{abstract}

Keywords: Outsourcing benefits, strategic management, Nigerian banks,

DOI: $10.7176 / \mathrm{EJBM} / 12-23-04$

Publication date:August $31^{\text {st }} 2020$

\section{Introduction}

The word outsourcing has attracted a lot of attention in the last decade, to the extent that managers and organizations consider whether in their best interest to carry out some activities within the organisation or have them performed by a third party. Outsourcing has been defined by (Irefin et al, 2012) as the process of replacing in-house provided activities by sub-contracting it out to external agents. In a layman's language, it does mean giving out work or activities that where once carried out by an organisation or a firm to an individual, organizations or parties who are specialized in doing such. Activities that are outsourced include but not limited to accounting and bookkeeping, tax preparation and filing, payroll processing, outsourcing creative work, social media marketing, hiring, event management and skills that are lacking within a firm or an organisation.

In Nigeria, the term outsourcing has gained much prominence that most industries if not all are involved in outsourcing. These ranges from hiring, tax filing e.t.c. as discussed above. Of these industries is the banking industry. The recent banking reforms in Nigeria has led to a drastic change in the mode and operations of the industry. Though the industry is not saturated any longer, but increased competition and uncertainties in the market has led to continuous innovations in order to survive, maintain competitive positions and grow. It is for these reasons that the industry utilizes diverse alternative means in an attempt to adjust to the rapidly changing external environment, outperform competitors and achieve strategic objectives. To the industry, dealing with multitude of employer's responsibilities, creating competitive packages to complying with the ever-changing government regulations can cause significant problem. Dealing with these problems might be too much for them to handle, in the light of this, one notably popular option is to outsource most of their responsibilities to a third party.

In the literature, several reasons have been highlighted as the rationale behind outsourcing in various organizations and firms. Green-Armytage \& Hawkins (1998).

The Outsourcing Institute (2000) and Smith et al (1998) pointed out four essential categories why firms or organisations outsource. These categories include financial, business, technical and political reasons. The financial reason subsumes operating cost reduction, budgets and cash infusion. The business reasons consist of core competencies and risk management. The technical reason includes improvement in technical services, access to new technology and access to talent. The political reasons include optimizing management time, energy and resources. The recent data released by the Naira metrics (2018) revealed that, Nigerian banks rely more on contract staff to boost their operations. These contract staffs are gotten through various human resource outsourcing agencies. The recently published data on sectoral breakdown of credit, ePayment channels and staff strength in the second quarter of 2018 shows that, the banking sector employed a total of 43,955 contract staffs as employees. This increased by $101 \%$ when compared to the previous year which stood around 21,837 . The data further revealed that contract staff as a percentage of total employees in the banking industries as risen from $26 \%$ at the start of 2017 to about $43.2 \%$ in 2018 . They further forecast going by this current trend that, the contract staff would surpass the $50 \%$ mark in the next few months.

Although, the various outsourcing activities and the rationale for outsourcing have been explained in the literature, there is the need to also focus on the benefit of outsourcing together with its associated risk to firms and 
organisations. Jegede (2015) identified five ways in which outsourcing activities are beneficial to an organisation. These benefits are, focused on core competence, reduction in staff head counts/size, curtailing and preventing industrial disputes, cost reduction in manager's burden and meeting targets. In another study by (Basel committee, 2005), it was stated that, the benefits of increasing use of outsourcing transcend cost reduction but also as strategy to minimize risk and improve core competency. In spite of all these benefits stated above, outsourcing also come with its own risk. These risks are manifested in loss of control on some key functions and likelihood of opportunistic expropriation by vendor (Ang and Cummings,1997; Lacity and Wilcocks, 1998). While outsourcing has profound benefits, it equally exposes firms to serious risks.

In less developed countries like Nigeria, outsourcing has also become trendy and a common practice among both private and public organizations and is a major element in business strategy. Most organization now outsources some of the functions they hitherto performed themselves. Despite the optimism about benefit associated with outsourcing, there is evidence that this process may incur significant risks (McFarLan \& Nolan, 1995; Lacity \& Hircheim, 1995). Globally regulators concern is how bank manage risk associated with a third party offering certain key services (Basel committee 2004).

It is however shocking and appalling that in spite of these revelation, very few or limited literature has identified with the activities of outsourcing, reasons why the rate of outsourcing is on the increase, the benefits and the perceived risk associated with outsourcing in the Nigerian banking industry. The objective of this study is to analyse various outsourcing activities, the rationale behind outsourcing, the benefit and risk of outsourcing in the Nigerian banking industry.

\subsection{Literature Review}

\subsection{Conceptual Review}

Several attempts have been made by scholars in the literature to categorize outsourcing and also define them in line of these categories. In of these literatures by Espino-Rodriquez et al (2006), they defined outsourcing as a "strategic decision that entails the external contracting of determined non-strategic activities or business processes necessary for the manufacture of goods of the provision of services by means of agreements or contracts with higher capability firms to undertake those activities or business processes with the aim of improving competitive advantage". It is the transfer of one or more internal activities of an organization to an external vendor. Duran and Duran (2009), define outsourcing to mean the process by which a firm contract its services to a third party. A concise definition of outsourcing is yet to be agreed upon, thus, the term outsourcing is used inconsistently.

Furthermore, outsourcing is commonly viewed as involving the contracting out of a business function that was previously performed in- house to an external provider. Wasner (1999) defines outsourcing as “...turning over to an external vendor the control of an in-house activity or activity for which an immediate ability exists of performing it internally." Wasner states that outsourcing is composed of a make or buys decision with transfer.

Domberger (1999), provided a more detailed definition of outsourcing. He defined outsourcing as a strategy of delegating organizational services or works to other party under a business agreement that includes time of service in relation to cost, quality and the timeliness of providing the services. To Beaument (2006), outsourcing can be said to be one sub-type of production to external entity such as a sub-contractor. Outsourcing has become an alternative which all major firms and organisation must embrace in order to remain relevant and competitive in the market. It also helps to increase efficiency, enhance service quality, accountability, values, reduce head counts and cash infusion and increase access to world class capability and sharing risk. The Outsourcing Institute, 2006). Therefore, outsourcing in the context of the study is defined as the process whereby activities traditionally carried out internally are contracted out to external body or bodies. It is therefore the transfer of an activity from an internal governing body to external governing body.

\subsubsection{Outsourcing services and Reasons for outsourcing}

Activities that are outsourced include; accounting and bookkeeping, tax preparation and filing, payroll processing, outsourcing creative work, social media marketing, hiring, event management and skills that are lacking within a firm or an organisation. Although, these might not represent an exclusive list of activities that are outsourced by various organisations. It however varies from organisation to organisation depending on their industry or their line of trade. For banking industry in Nigeria, their outsourcing activity is majorly in the area of human resource commonly known as contract staff. Several rationales have been giving for outsourcing activities, they include;

\section{Cost driven outsourcing}

There is some literature that suggests that most outsourcing is primarily motivated by the organizations efforts to reduce costs (Meckbach, 1998). Much of the literature identifies the desire to save costs as an explanation for why outsourcing occurs (Arnold 2000, Aubert et al 1996; Willocks et al,1995). In theory, outsourcing for cost reasons can occur when suppliers' costs are low enough that even with added overhead, profit, and transaction costs, suppliers can still deliver a service for a lower price (Bers, 1992; Harler, 2000). Specialization and economies of 
scale are mechanisms used to achieve this level of efficiency (Kakabadse and Kakabadse, 2000). A desire to save indirect costs may also drive outsourcing. Having fewer employees requires less infrastructure and support systems. (Huber,1993) which may result in a nimbler and efficient organization. Some organization outsourcing to achieve better cost control (Alexander and Young, 1996) while others try to shift fixed cost into variable costs.

\section{Strategy Driven Outsourcing}

More recently the main drivers for outsourcing appear to be shifting from cost to strategic issues such as core competence and flexibility (Di Romualdo and Gurbaxani ,1998). In general, the literature supports outsourcing as a strategy which may offer improve business performance on numerous dimensions. (Brandes et al 1997). Perhaps, the most often sited strategic reasons for outsourcing is to allow the organization to better focus on its core competences (Quinn 1999). Because of intense competition, organizations are forced to reassess and redirect scarce resources (works management 1999). Resources are typically redirected to where they make the greatest positive impact namely the organizations core functions.

\section{Politically - Driven Outsourcing}

There are several reasons why a public organization may behave differently than a private firm and therefore may have different outsourcing motivation. Avery (2000) argues that the performance of a service by the public laboratory is not based on market demand or profitability. The issue may be more social than economic. He uses the example of the public organization detecting a virus or health hazard, whereas the private organization would be in the business of treating the infected with a fee. Even when the services appear to be identical, the product may be very different. Industry performs a service to make money while public organization attempts to ensure the general wellbeing a different goal and mission. So, while cost and strategy may drive private firms the desire for the general wellbeing of citizens may drive outsourcing by public organizations. These factors relate to the internal and external environment faced by the organization.

\subsubsection{Expected Benefits of Outsourcing}

Overall, six reasons can be deduced from the theoretical and empirical literature to account for the adoption of outsourcing, the first is the managers have wanted to reduce cost and increase efficiency which the economic literature argues can be achieved by adopting certain structural forms (Williamson, 1979). In fact, cost savings due to outsourcing can be quite significant. In a survey of 7500 public organization in Australia, the outsourcing of cleaning services saved an average of 46 percent over in-house performance of the service (Domberger and Ternandez, 1999). A desire to save indirect costs may also drive outsourcing. Having fewer employees requires less infrastructure and support systems which may result in a more nimble and efficient organization. Focusing on Core Competitive advantage is a second reason. In this instance, the specialized nature of an organization, competitive advantage is raised by Porter's (1980) corporate strategy theory as important when choosing which governance structure is put in place. In this regard, those functions or activities regarded as non-core can therefore be outsourced.

The third reasons being to introduce workforce flexibility by outsourcing peripheral workforce is based on Atkinson's (1984) flexible firm model. In contending that labour, be divided into core and peripheral segments, workforce flexibility is maximized with the core segment providing functional skills and the peripheral segment providing numerical skills. The labour market and political literature (Burgess and Macdonald 1990, Pfeffer 1992, Benson and Ieronimo 1996) suggests that a fourth reason for outsourcing is to reduce the problem of managing industrial relations. In this regard, the use of outsourcing is said to increase the power of management over labour and weaken the power of trade unions. The personal objective of decision makers is fifth reason for outsourcing and is primarily found in the political and public choice literature dealing with this issue (Preffer 1994, Down 1967) One example is the use of outsourcing to increase the proportion of white-collar employees at the expense bluecollar employees, a move aimed at improving the status of managers. (Dunleavy, 1991).

The sixth reason is the desire to align public sector agencies with the ideology of the government providing the funding (Downs, (1967, Feignbaum and Henig, 1994). The ideology advocated outsourcing, alongside private sector competition, a reduction in the size of the public sector and a decrease in the power of labour. However, despite the optimism about the benefits associated with outsourcing, there is evidence that this process may incur some significant risks (McFarlan and Nolan 1995, Lacity and Hirschheim 1993).

\subsubsection{Risks and Concerns about Outsourcing}

Some organizations do not achieve the expected benefits from outsourcing. For example, a report quoted in Lonsdale (1999) and McIvor (2000) suggested only 5\% of companies surveyed achieved significant benefits from outsourcing Lonsdale (1999) and Cox (2006) highlight reasons for this; focusing on achieving short-term benefits, lack of formal outsource decision-making processes including medium and long-term cost benefit analyses, increased complexity in the total supply network. 
In the public sector there are other concerns. Sourcing clinical services with private sector firms has been called "creeping privatization" contrary to government policy (Labour Party 1997) and the ethos of public sector healthcare system (Whitfield and Dix 1998). Marshall (2002), concluded that insufficient attention had been paid in general to the management of the outsourced activity and that outsourcers do not receive guidance on how to approach the task.

As found in research in other industries, (Young and McNeil 2000), the effects of outsourcing did not always align with manager's expectations with several contracts being eventually terminated due to poor quality, excessive monitoring or the contractors' inability to meet the specifications. Cost saving and increased efficiency generally resulted alongside a downsized labour force. But even when outsourcing did not proceed after-market testing, the results were similar with the use of other change processes. Such as introducing new technology, changing departmental structures and promoting workforce flexibility". As Young (2002) states, the research "points to the complex interrelated nature of the use of downsizing to change workers acceptance of change, which includes outsourcing and the use of outsourcing to reduce employee numbers".

Contracting out services/activities entails significant loss of control over the performance of the activities. Associated with this loss or control are two basic risk, shirking and opportunities bargaining. Shirking refers to the vendor's under-performance on the contracted activities and opportunities bargaining refer to a vendor's ability to demand higher than market prices. An outsourcer can be subjected to opportunities bargaining when he or she is "locked-in" to a single vendor and would have to incur considerable cost to switch to another (Ngwenyama and Bryson 1999). To minimize the risk of shirking, the outsourcer can invest in monitoring and coordinating mechanism.

\subsection{Empirical Review}

Quite a few studies have been done on the analysis of outsourcing activities and rationale for outsourcing in Nigeria let alone with regards to the banking industry. The few ones around have shown that the major rationale behind outsourcing is cost reduction, although, several others reasons have also been discovered as rationale behind firms and organisation involvement in outsourcing. Jegede (2015), conducting a study on outsourcing and performance of commercial banks in Lagos state. The results identified the need to focus on core activities, cost reduction, technical considerations, increase productivity and performance as the rationale behind outsourcing by banks in Lagos state. He further opined that outsourcing activities have been beneficial to banks in Lagos state.

Federal Reserve Bank of New York (1999) conducted survey on banking industry practices for outsourcing arrangements. Findings suggest that banks outsource financial services for several reasons, such as, enhanced performance; costs reduction; access to superior expertise; and strategic reasons. In addition, the study indicates that although there are many benefits derived from outsourcing of financial services, the arrangement give rise to potential risks. The risks identified are: strategic, reputation, credit, compliance, transaction and country risk. Similarly, in 2004 Federal Reserve Bank of San Francisco, conducted survey on outsourcing by financial services firms, and notes a number of motives for outsourcing, namely, operational efficiency; efficient use of resources; and quick and reliable service delivery.

Similarly, a survey conducted by European Central Bank in 2004 reveals that although the benefits of outsourcing are evident, in practice, many banks believe that outsourcing introduces new challenges and risks. The study highlights the benefits of outsourcing, suggesting; cost reduction; access to better technology and infrastructure and strategy of focusing on core activities; free scarce resources; quality services; and flexibility. As with US studies, the European study also reveals several risks associated with outsourcing, namely, operational, legal, strategic risk, country risk reputational risk, loss of flexibility, loss of control and cultural/social problems.

Pujals, (2004) conducted a study on offshore outsourcing in the European Union financial services industry. Results of the study indicate that banking institutions may choose to outsource certain activities for various motives. Some of the motives cited are: cost reduction, access to new technology, focus on core activities, improvement of quality of services and greater flexibility. In addition, the study identified the following risks associated with outsourcing of financial service: loss of control over service, operational risks, loss of internal skills, loss of flexibility, cultural and social problems, technical constraints, decline in quality and competitive advantages. Sameen, Imran \&Sabri (2006) conducted multi country study to assess the range of health services contracted out the process of contracting and its influencing factors in 10 countries of the Eastern Mediterranean Region. Their study revealed that most countries undertook contracting to improve access, efficiency and quality of health services.

They concluded that outsourcing of health services is an evolutionary process and that all countries developed and developing will pass through a learning phase before contracting is recognized as an effective management and regulatory tools $\{$ Bulletin of WHO, 2006; 84(11)\}.

Price Waterhouse Coopers (1999) surveyed, 300 of the largest global companies and found that $73 \%$ were outsourcing to some degree. The most common activities outsourced were benefits administration, payroll, logistics, real estate management and internal audits $95 \%$ of respondents reported satisfaction with outsourcing, 
$63 \%$ had realized anticipated cost savings and $50 \%$ believed to outsourcing had in the three years prior to the survey increased in importance. The primary reasons cited for outsourcing were: to focus on core competencies, enhance shareholder value and avoid technology investment required to enhance efficiencies (Simke, 2000).

With reference to outsourcing failure, Hayward comments Fans of the approach rave about cost savings, its critics point to high profile disasters $(2002$, p. 26). Two extreme disaster examples are the Hatfield (UK) rail crash in October 2000 and the September 112001 terrorist attack on New York. Both of these events result in substantial criticism levied against outsourcing. Railtrack UK has been criticized for outsourcing its maintenance and the US airline industry for outsourcing security and baggage handling (Hayward, 2002 p. 27). Young and Huang (2000) looked at outsourcing of information systems and argued that five factors (management, strategy, Transaction Cost Economics, technology and quality) should be considered when considering the outsourcing decisions. Based on these factors, they propose a decision model to assist managers when deciding whether to outsource individual Information Systems.

Many studies have been conducted over the last decade to assess the nature and motives of outsourcing. As early as the 1960s, Baumol (1967) argued that one of the major reasons for the growth of service section could be linked to service outsourcing in the manufacturing industries. The fact that manufacturing industries to an increasing extent could outsource less efficient service activities and focus on their core competencies led to the significant productivity gains in the industry and increased productivity gap between the manufacturing industry and the service sector a phenomena that was later called "Baumol's disease".Fixler and Siegel (1999) provide some insights into outsourcing and its productivity impact on the services sector.

Their empirical evidence suggests that outsourcing led to short-run reductions in service sector productivity but that productivity improvement can be expected especially for business services once outsourcing of services by manufacturing firms will subside relative to production capacity in the service sector. They also argued that productivity in the services sector will increase as outsourcing by service firms increases although they produce no direct evidence of this.

Akinola and Longe (unknown date) carried out a study on Information Systems Outsourcing in Nigerian: trends, perceptions and effectiveness. The study used a self-constructed questionnaire. Employing chi square and descriptive analysis, the study revealed that information technology equipment acquisition, software development and web-hosting are the most common outsourced services. He further provides evidence that the need to reduce cost and improved quality as the rationale behind outsourcing in Nigeria.

Davis and Knox (unknown date) examined the reasons why organisations outsource information technology system in Australia through personal interview with different senior managers from different organisations ranging from public listed companies, statutory authorities to state government agencies. The study found that there are thirteen reasons or rationale responsible for outsourcing among various organisations. These reasons are further constricted into five categories which include financial, business, technical, political and environmental reasons. They also found out that functions that are repetitive, operational and are of less strategic importance are mostly outsourced. Their findings further revealed that top reasons for outsourcing given by most managers interviewed fall within the business and technical reasons.

Inegbedion (2016), in his study on outsourcing of human resources functions and organizational competitiveness in Nigeria with his focus on First Bank, Airtel Nigeria and National Board for Business and Technical Education (NBBTE) in Benin city. The study discovered that cost reduction is one of the major rationale for outsourcing among these organisations. He further stressed that outsourcing is done to enhance competitiveness.

\subsection{Research Methodology \\ 3.1 research Design}

The paper adopted an ex-post descriptive research and the study area was determined using geographical and operational approaches. The geographical study area was taken as entire banking industry in Nigeria as a whole but with much emphasis on banks that have their headquarters in Lagos. The choice of this study area is because of easy accessibility and the need to have focus without compromising the representativeness and adequacy of information. The study concentrated only on Lagos since the headquarters of all the banks except Unity Bank are in Lagos. Since the outsourcing decisions are taken from the headquarters then it is assumed that the best focal point for the study should be the head office of each bank. A preliminary interaction with some of the executives of these banks showed that outsourcing activities and decisions to outsource are policy issues that are taken at the management level. Also most of the outsourcing firms are located in Lagos and hence focusing on Lagos allows easy access and opportunity to meet those that are directly involved in outsourcing activities with banks at different levels.

Hence, the entire employees and employers as well as the vendors of the 20 banks (See appendix A) that scaled through consolidation and merging activities in Nigeria as at 2013 when the research were taken constitute the population for the study. This population comprised both outsourced and core staff as well as the outsourcing vendors of the banks in Nigeria and they were classified into four categories: 
(i) Management staff of the existing banks

(ii) Non-management staff that are core staff of these banks

(iii) The outsourced staff of the banks.

(iv) The vendors of these outsourced activities and staff of these banks.

The continuous retrenchment in the banking industry has made it difficult to ascertain with precision the exact number of staff in most these banks. Retrenchment and recruitment is a continuous process in the Nigeria banking industry and any figure given is only relevant as that particular time only". A study by Gunu (2009) and a report of bank supervision by CBN (2010) however, put the number of staff in Nigerian banks in 2008 at 88,902. Projecting this figure further to 2012 shows further that the employment in the banking industry should have increased by $10 \%$ after the consolidation and the employment in the sector should be about 110,000. Both random sampling and purposive sampling techniques were adopted. The purposive sampling will be used to determinate the unit to survey. The unit must be those units that have something to do with outsourcing decision while simple random sampling will then be used to select the staff to interview or administer questionnaires.

\section{Research Instrument and Data Collection Technique}

A structured questionnaire was developed and sent to staff members of the purposively selected 20 banks who were in charge of finance and strategy functions. The questionnaire was sent to the following categories of people:

(i) managers,

(ii) staffs and customers at the headquarters or headquarter branches of the selected banks.

(iii) Identified vendors of the outsourcing activities of the banks

Fifty questionnaires were administered to each of the selected banks. Since the pilot study revealed that all banks have participated or currently involved in one or two outsourcing efforts, hence, the survey was conducted on all the 20 banks in Nigeria, using random sampling. Since all of the banks except Unity bank have their headquarter in Lagos and the south west has the largest proportion of the bank branch network in the country accommodating more than 65 per cent of bank branch network as at 2010 ( CBN 2010). The self-administered questionnaire was sent to each head office and at least one state zonal office in the south west part of the country.

The respondents were selected using simple random sampling technique to give each member a chance to be involved in the study without any element of bias. The total sample size drawn from the selected 20 banks was 500 (25 respondents from each bank) for the quantitative instrument (questionnaire), while for qualitative instrument, 20 In-depth Interview (IDI). The major advantage of using the questionnaire is that it provides opportunity to categorize the responses and its ability to elicit information where many respondents are involved. The IDI was used because it gave the opportunity to probe deeper especially on issues the questionnaire may not extensively deal with and to complement data generated through the questionnaire. Interview will be conducted.

\section{Measurement of variables}

Each of the objectives raised for this study is represented by a set of indicators which form the question in the survey. Questions regarding the perceived risk will take the form of stating a risk and asking the respondent to rate the risk on the following scale; very high, high, neutral, low, and very low. Questions on the perceived benefits also take similar approach in which a statement will be given and the respondents will be asked to state their level of agreement on the following scale: strongly agree, agree, neutral, disagree and strongly disagree. In likert scale, very high and strongly agree take the value of 1 while high and agree take the value of 2 while neutral takes the value of 3 . Disagree and strongly disagree take the value of 4 and 5 respectively.

Therefore, on the question of perceived benefits and risks, respondents answering one 1 or 2 are regarded as positive on the benefits outlined in the questioned. Any respondent answering 3 can be regarded as neutral and respondents answering 4 or 5 can be regarded not in support of the benefits. In case of perceived risks, respondents answering 1 or 2 can be said to perceive outsourcing as risky business, respondents answering 3 can be said to be neutral or undecided, while respondents answering 4 and 5 can be said to perceive outsourcing as not risky. The Independent variables are: employment status (whether core or contract staff, operating cost of the bank, bank size, total number of employee, proportion of staff outsource. Whether the bank outsources or not, Types of services outsourced, level of outsourcing (partial or full).

In addition, the survival of an enterprise depends on its customers; hence customers are the driving force of outsourcing programmes (Lewis, 2000; Kotler, 2000). Customer retention is therefore crucial to the survival of many companies, and this could be achieved through good customer service management. When there is high customer retention rate, it indicates that these retained customers are satisfied with the services offered by the enterprise, and are likely to invite friends and members of their families (Kotler et al., 2001). An improved CSM can also expedite and enhance customer re-buy, which often resulted to improved customer satisfaction, customer retention and relationship management (Khong, 2005), all being an indication of improved business performance. Therefore CSM is an important endogenous construct in determining organisation success in all outsourcing efforts, since superior customer value will lead to superior performance (Mullins and Larreche, 2006). However, since the 
purpose of this study is to examine the perceived impact of successful outsourcing on PBPM, it is expected that the former outsourcing will positively improve the latter (PBPM) (Elmuti, 2003; Quinn, 2000, Khong 2005)

\subsection{Validation of Research Instrument}

To refine and validate questions asked, prior to banks' survey, the questionnaire will be discussed independently with staff of selected banks. Two-stage technique of validation will be adopted for the research instrument to be used for this study. In the first instance, the draft of the questionnaire will be given to experts in social and financial management research. For instance, after the questionnaire has been drafted, it will be given to some researchers in Nigerian Institute of Social and Economic Research (NISER) Ibadan and Centre for Industrial Research and Development (CIRD) at Obafemi Awolowo University, Ile-Ife. In addition, copy of the questionnaire will be given to other notable academics in the faculty who had, in one period or the other engaged in using similar research instrument to elicit information from respondents with similar traits on issues under study. The comments and suggestions of these groups of people will be used to improve the quality and to ensure both face and content validity of the instruments.

In the second stage, the revised questionnaire, based on the experts' suggestions, will then be subjected to field test before developing the final copy. To do this, a pilot test will be conducted, and the feedback collected will then be used to further improve the design and content of the questionnaire. For example, there may be concerns on the bank staff to be selected from the pilot test about the length of the questionnaire suggesting a shorter version to be used to increase the response rate. The structure of some of the open questions may have to be reframed into category questions which are less time consuming. Special attention will be paid to questions that the respondents deliberately omitted and/ or felt strong about. Efforts will be made to reframe such questions and if necessary replaced them with others that will achieve the same results but which are likely to be more acceptable to the respondents. The comments, suggestions and corrections made by the respondents will then be collated and used to improve the quality of the final questionnaire for the study. Also, the use of multiple data sourcesQuestionnaire and In-Depth-Interview (IDI) will also enhance the study data validity. Based on comments of the participants, the questionnaire will be modified and finalized.

\section{Technique of Data Analysis}

In achieving the first objective which relate to the type of activities outsourced and rationale for outsourcing such activities, descriptive statistics will be adopted. In these descriptive, statistical tools such as table graphs and chart will be used to describe the socio demographic and economic profile of the banks and the workers in these banks that responded to the questionnaires. The analysis involved the types of activities outsources and the rationale for outsourcing the, the responses from the different banks will be compared and examined through the use of cross tabulation and other statistical tools such as chi square, t-test, F-test and analysis of variation (AVOVA) to determine whether there is significant differences in the degree of familiarity and utilization of outsourcing as well as the types of activities outsourced. Also the rational for outsourcing such activities will be examined and analyzed based on these statistical tools

The perceived benefits and risks was analyzed descriptively and statistically. The respondents were expected to identify the benefits and risks and they were expected to rank their responses according to their perception of importance and severity. The responses were analyzed and compared using the chi-square to determine the significance in different perception of the respondents. This analytical approach was also adopted to determine the factors associated with success or failure of outsourcing in the Nigerian banking industry.

\subsection{Presentation and Analysis of Results Descriptive Statistics of Respondents}

From table 1.the percentage distribution of respondents' gender characteristics shows that an aggregate of five hundred (500) respondents (bank workers) were randomly selected, involving two hundred and fifty-seven males (257) or $51.4 \%$ and two hundred and forty-three females (243) or $48.6 \%$. This implies that there were more male respondents than females. Though the percentage difference is just $2.8 \%$, this pattern notwithstanding, the representation of the gender still seems balanced and sufficiently representative of the gender composition of the bank workers respondents.

The age composition of the respondents as in table 1 above shows that 93 or $18.6 \%$ of the respondents are under the age of 25 , while 331 or $66.2 \%$ of the respondents fall between 26-35 years. Meanwhile 68 or $13.6 \%$ of the respondents are between 36-45 years, while 6 or 1.2\% of the respondents ranges between $46-55$ years, and the remaining 2 or $0.4 \%$ respondents were above 50 years of age. Thus, the survey revealed that most of the bank workers are youths within the age brackets of 26 to 35 years of age $(66.2 \%)$, as complemented with those below 25 years of age $(18.6 \%)$. This indicates that about $84.8 \%$ of bank workers are majorly youths of ages below 25 years and up to 35 years. Only $13.6 \%$ are between $36-45$ years, while just $1.2 \%$ are between $46-55$ years and very few $0.4 \%$ are above 50 years of age. Hence, it can be established that the issue of ageing service is not applicable 
in the banking sector as most of bank workers are dominantly youths.

Also table 1 indicates that only $2(0.4 \%)$ of the respondents hold a secondary school certificate, $198(39.6 \%$ are polytechnic graduates, 219 or $43.8 \%$ respondents hold first degree certificate and 81 or $16.2 \%$ hold postgraduate certificate. Thus, the study divulged that a larger percentage of bank workers $(43.8 \%)$ are university graduates, as complemented by graduates from polytechnics and few of $16.2 \%$ have postgraduate certificates. Meanwhile $0.4 \%$ of the respondents are secondary school leavers who are composed of Security staff, Cleaners and Bank Auxiliary workers. However, the study survey established that most of the bank workers are qualified graduates.

Table 1: Demographic profile of Respondents

\begin{tabular}{lll}
\hline Gender & Frequency (500) & Percentage (100\%) \\
\hline Male & 257 & $51.4 \%$ \\
Female & 243 & $48.6 \%$ \\
\hline Age of Respondents & & \\
Under 25 & 93 & $18.6 \%$ \\
$26-35$ & 331 & $66.2 \%$ \\
$36-45$ & 68 & $13.6 \%$ \\
$46-55$ & 6 & $1.2 \%$ \\
Over 55 & 2 & $0.4 \%$ \\
\hline Level of Education & & \\
Secondary School & 2 & $0.4 \%$ \\
Polytechnic & 198 & $39.6 \%$ \\
First Degree & 219 & $43.8 \%$ \\
Postgraduate & 81 & $16.2 \%$ \\
\hline
\end{tabular}

\section{Socioeconomic Characteristics of Respondents}

Table 2 above shows the various sections of the bank where each of the respondents belong to. This include; Operations, Marketing, Human resources, Legal and admin, Treasury, Inspection, Control, Information technology and others as Security and Cleaning. Among the total of 500 respondents examined, $232(46.4 \%)$ work in Operations, 146 (29.2\%) are in Marketing section, 24 (4.8\%) are in Human Resources section, while 23 (4.6\%) are in Legal and Admin section. 20 or $4.0 \%$ of the respondents are in Treasury, 16 or 3.2\% work in Inspection section, 25 or 5.05 are in Control, while 12 or $2.4 \%$ are in Information and technology section and the remaining 2 or $0.4 \%$ belongs to Others as Security and Cleaning sections. Thus, the survey established that a relatively larger percentage of the bank workers examined work in Operations section and more others are in the Marketing section. This shows that banks recruit more staff to Operations and Marketing sections than other sections of the bank.

From table 2, the position of each of the respondents within the banks are divided into three; Executive/senior management, Middle management and Junior management. The survey shows that 28 or $5.6 \%$ of the respondents are in Executive/senior management, while 172 or $34.4 \%$ belong to Middle management and the remaining 300 or $60.0 \%$ fall into Junior management category. Hence, the study ascertained that most and more than average of the bank workers examined are in Junior management category, and a considerable number of $34.4 \%$ are Middle management staff, while only very few number of 5.6\% have risen up to the top Executive/senior management position. Table 2 depicts that out of the total of 500 respondents examined, 315 or $63.0 \%$ have spent between $0-5$ years in the bank service, 162 or $32.4 \%$ of the respondents have spent $6-10$ years, 20 or $4.0 \%$ have used 11-15 years, while 2 or $0.4 \%$ have spent up to $16-20$ years and just 1 or $0.2 \%$ have stayed up to $21-25$ years in the banking service. This assessment shows that most of bank workers only stay for an average of 5 to 10 years of banking services, while less than $5.0 \%$ stay up to $11-15$ years and only $0.6 \%$ have up to 16 to 25 years of banking experience. Thus, this suggests many of the bank workers are either laid off or personally withdraw from service after certain period of time, thereby affirming that the concern of permanent staffing is not peculiar to the banking sector. 
Table 2: Bank Related Characteristics of Respondents

\begin{tabular}{lll}
\hline Which section of bank do you work? & Frequency & Percentage \\
\hline Operations & 232 & $46.4 \%$ \\
Marketing & 146 & $29.2 \%$ \\
Human Resources & 24 & $4.8 \%$ \\
Legal \& Admin & 23 & $4.6 \%$ \\
Treasury & 20 & $4.0 \%$ \\
Inspection & 16 & $3.2 \%$ \\
Control & 25 & $5.0 \%$ \\
Information Technology & 12 & $2.4 \%$ \\
Others please, specify (Security, Cleaning etc.) & 2 & $0.4 \%$ \\
\hline Position in the Bank & & \\
Executive/ Senior Management & 28 & $5.6 \%$ \\
Middle Management & 172 & $34.4 \%$ \\
Junior Management & 300 & $60.0 \%$ \\
\hline Number of years in the service of the bank & & \\
0-5years & 315 & $63.0 \%$ \\
6-10years & 162 & $32.4 \%$ \\
$11-15 y e a r s$ & 20 & $4.0 \%$ \\
16-20years & 2 & $0.4 \%$ \\
21-25years & 1 & $0.2 \%$ \\
\hline
\end{tabular}

\section{Types of Activities Outsourced}

Thus, the study ascertained from the responses obtained that, out of the various bank services/activities highlighted in the questionnaire, 18 services has been outsourced in one way or the other over the past five years. The services which include: Security, Cleaning, Recruitment, Training, Human Resources, ATM, Information Technology, Advert and Promotion, Consultancy Services, Maintenance, Call Centre, Internet Banking, Card Processing, Debt Collection, Internal Audit, Pay-roll, Customer Information Verification and Data Centre in the respective order. Meanwhile, it was established that options as Product Design, Account Opening and Processing and Others (yet unspecified) have not been outsourced at all.

As depicted in Table 3 above, the responses to the question on the activities being traditionally carried out that are now contracted to external providers, shows that out of the total 500 responses obtained, Security has 426 $(85.2 \%)$ with mean score of 0.85 to rank number 1 , Cleaning has $366(73.2 \%)$ with mean score of 0.73 to rank 2nd, Recruitment has 361 (72.2\%) with mean score of 0.72 ranking 3rd, Training has 268 (53.6\%) with mean score of 0.54 to rank 4th, while Human Resources has 236 (47.2\%) with mean score of 0.47 to rank 5th. ATM has 107 $(21.4 \%)$ responses with mean score of 0.21 ranking 6 th, 75 or $15.0 \%$ responses with mean score of 0.15 goes to Information Technology to rank 7th, Advert and Promotion follows with 74 or $14.8 \%$ responses with same mean score of 0.15 .

Consultancy Services ranked 8th with mean score of 0.14 and 69 (13.8\%) responses, Maintenance has 63 $(12.6 \%)$ with mean score of 0.13 to rank 9 th, Call Centre follows with $37(7.4 \%)$ with mean score of 0.07 to rank 10th, Internet Banking has $25(5.0 \%)$ with mean score of 0.05 ranking 11th, Card Processing has $15(3.0 \%)$ with mean score of 0.03 to rank 12th, as followed by Debt Collection with 13 (2.65) and equal mean score of 0.03 . Internal Audit has $8(1.6 \%)$ with mean score of 0.02 to rank 13th, Pay-roll has $7(1.4 \%)$ with mean score of 0.01 ranking 14th alongside Customer Information Verification with $6(1.2 \%)$ and same mean score of 0.01 and also Data Centre with $5(1.0 \%)$ and equal mean score of 0.01 . Those options with no responses are; Product Design, Account Opening and Processing, and Others with 0 (0.0\%) and mean score of 0.0 . 
Table 3: Activities Outsourced by Banks

\begin{tabular}{lllll}
\hline $\begin{array}{l}\text { Services outsourced in the Nigerian Banking } \\
\text { Industry }\end{array}$ & $\begin{array}{l}\text { Frequency } \\
\text { (Total = 500) }\end{array}$ & $\begin{array}{l}\text { Percentage } \\
\text { (Total = 100\%) }\end{array}$ & $\begin{array}{l}\text { Mean } \\
\text { Score }\end{array}$ & Rank \\
\hline Security & 426 & $85.2 \%$ & 0.85 & 1 \\
Cleaning & 366 & $73.2 \%$ & 0.73 & 2 \\
Recruitment & 361 & $72.2 \%$ & 0.72 & 3 \\
Training & 268 & $53.6 \%$ & 0.54 & 4 \\
Human Resources & 236 & $47.2 \%$ & 0.47 & 5 \\
ATM & 107 & $21.4 \%$ & 0.21 & 6 \\
Information Technology & 75 & $15.0 \%$ & 0.15 & 7 \\
Advert and Promotion & 74 & $14.8 \%$ & 0.15 & 7 \\
Consultancy Services & 69 & $13.8 \%$ & 0.14 & 8 \\
Maintenance & 63 & $12.6 \%$ & 0.13 & 9 \\
Call Centre & 37 & $7.4 \%$ & 0.07 & 10 \\
Internet Banking & 25 & $5.0 \%$ & 0.05 & 11 \\
Card Processing & 15 & $3.0 \%$ & 0.03 & 12 \\
Debt Collection & 13 & $2.6 \%$ & 0.03 & 12 \\
Internal Audit & 8 & $1.6 \%$ & 0.02 & 13 \\
Pay-roll & 7 & $1.4 \%$ & 0.01 & 14 \\
Customer Information Verification & 6 & $1.2 \%$ & 0.01 & 14 \\
Data Centre & 5 & $1.0 \%$ & 0.01 & 14 \\
Product Design & 0 & $00.0 \%$ & 0.00 & 15 \\
Account Opening and Processing & 0 & $00.0 \%$ & 0.00 & 15
\end{tabular}

Source: Field Survey of Bank Workers in Lagos

\section{Degree of Outsourcing}

Table 4 depicts that out of the services outsourced in the past five years, the degree of outsourcing varies in accordance with the responses obtained. It shows that ATM is $20.2 \%$ partially outsourced, $4.6 \%$ fully outsourced and is $2.2 \%$ under consideration. Card Processing is $1.2 \%$ partially outsourced, $0.2 \%$ fully outsourced, $0.2 \%$ under consideration and $0.8 \%$ reintegrated function. Internal Audit is $0.2 \%$ partially outsourced, $2.4 \%$ fully outsourced and $2.4 \%$ decided against. Human Resources is $18.8 \%$ partially outsourced and $30.8 \%$ fully outsourced. Information Technology is $11.0 \%$ partially outsourced, $4.6 \%$ fully outsourced, and $2.4 \%$ under consideration. Internet Banking is $1.4 \%$ partially outsourced, $0.6 \%$ fully outsourced and $1.2 \%$ under consideration. Security is $1.4 \%$ partially outsourced, $87.0 \%$ fully outsourced and $0.2 \%$ under consideration. Training is $30.4 \%$ partially outsourced, $26.4 \%$ fully outsourced and $11.4 \%$ under consideration. Cleaning is $3.6 \%$ partially outsourced, $75.4 \%$ fully outsourced and $0.2 \%$ under consideration. Advert and Promotion is 3.2\% partially outsourced, 3.05 fully outsourced and $7.8 \%$ under consideration.

Customer Information Verification is $0.2 \%$ partially outsourced, $0.2 \%$ fully outsourced and $0.2 \%$ under consideration. Recruitment is $4.0 \%$ partially outsourced, $71.0 \%$ fully outsourced and $0.2 \%$ under consideration. Sales/Marketing is $0.8 \%$ partially outsourced, and $0.4 \%$ fully outsourced. Debt Collection is $1.2 \%$ partially outsourced, and $0.6 \%$ reintegrated function. Account Opening and Processing is $0.4 \%$ decided against while Product Design is 3.8\% decided against and 0.6\% reintegrated function. Pay-roll is $1.8 \%$ fully outsourced, $0.4 \%$ under consideration and $0.8 \%$ decided against. Consultancy Service is $1.8 \%$ partially outsourced, $1.0 \%$ fully outsourced, $8.4 \%$ under consideration and $0.4 \%$ reintegrated function. Call Centre is $0.4 \%$ fully outsourced, $3.2 \%$ under consideration and $0.2 \%$ reintegrated function. Maintenance is $0.6 \%$ partially outsourced, $7.0 \%$ fully outsourced, $14.6 \%$ under consideration and $0.4 \%$ reintegrated function. Data Centre is $2.0 \%$ fully outsourced, $2.4 \%$ under consideration and $0.4 \%$ decided against, while others (yet unspecified service) has no responses. In the light of the responses analysed, the study established that among other activities/services of the bank highlighted, Security occupies the highest degree $(87.0 \%)$ of the services that has been fully outsourced. Cleaning service with $75.4 \%$ has the next highest of services that have been fully outsourced. Recruitment service follows with $71.0 \%$ in the degree of services been fully outsourced. In similar consideration, Human Resource has a considerable degree of $30.8 \%$ fully outsourced. However, Training service and ATM service are more considered to be partially outsourced with $30.4 \%$ and $20.2 \%$ degrees respectively. 
Table 4: Degree of Outsourcing in Banks

\begin{tabular}{|llllll|}
\hline & Partia & & Under & Decided & Reintegrated \\
& 1 & Full & Consideration & Against & Function \\
\hline ATM & 20.2 & 4.6 & 2.2 & 0 & 0 \\
Card Processing & 1.2 & 0.2 & 0.2 & 0 & 0.8 \\
Internal Audit & 0.2 & 2.4 & 0 & 2.4 & 0 \\
Human Resources & 18.8 & 30.8 & 0 & 0 & 0 \\
Information Technology & 11 & 4.6 & 2.4 & 0 & 0 \\
Internet Banking & 1.4 & 0.6 & 1.2 & 0 & 0 \\
Security & 1.4 & 87 & 0.2 & 0 & 0 \\
Training & 30.4 & 26.4 & 11.4 & 0 & 0 \\
Cleaning & 3.6 & 75.4 & 0.2 & 0 & 0 \\
Advert \& Promotion & 3.2 & 3 & 7.8 & 0 & 0 \\
Customer & & & & & 0 \\
Verification & 0.2 & 0.2 & 0.2 & 0 & 0 \\
Recruitment & 4 & 71 & 0.2 & 0 & 0 \\
Sales/Marketing & 0.8 & 0.4 & 0 & 0 & 0.6 \\
Debt Collection & 1.2 & 0 & 0 & 0 & 0 \\
Account Opening \& Processing & 0 & 0 & 0 & 0.4 & 0.6 \\
Product Design & 0 & 0 & 0 & 3.8 & 0 \\
Pay-roll & 0 & 1.8 & 0.4 & 0.8 & 0.4 \\
Consultancy Services & 1.8 & 1 & 8.4 & 0 & 0.2 \\
Call Centre & 0 & 0.4 & 3.2 & 0 & 0.4 \\
Maintenance & 0.6 & 7 & 14.6 & 0 & 0 \\
Data Centre & 0 & 2 & 2.4 & 0.4 & \\
\hline
\end{tabular}

\section{Rationale for Outsourcing}

Table 5 above reveals that out of the total 500 (100\%) respondents examined, $350(70 \%)$ indicated "technical convenience and efficiency" as a major rationale for outsourcing, 292 (58.4\%) indicated "increase productivity/performance" as a key reason, 223 (44.6\%) respondents indicated "the need to focus on core activities" as a factor, 208 (41.6\%) specified 'improvement of service delivery and quality' as a factor, 207 (41.4\%) specified "to meet changing customers' needs" as a factor, 195 (39.0\%) respondents specified "a means to obey government directive to downsize" as factors, while $102(20.4 \%)$ respondents suggested "provision of uninterrupted services" as a factor influencing outsourcing decisions in the Nigerian banking industry. In the same vein, 65 (13.0\%) respondents indicated "the need to realize cost efficiency" as a factor, 55 (11.0\%) respondents chose "to make more efficient use of labour, capital, information technology and human resources" as a factor, 27 (5.4\%) respondents selected "to prevent and reduce labour related issue" while $26(5.2 \%)$ of the respondents picked "to gain access to new talent and technology" as a factor. "Exhibition of professionalism" follows as a factor with 13 $(2.6 \%)$ responses, while the remaining 5 or $(1.0 \%)$ respondents suggested "easy availability of vendors with expertise and economies of scale" as a likely factor influencing outsourcing in the bank sector. From the foregoing, it can be established that outsourcing decision in the Nigerian banking industry is significantly influenced by factors as; Technical convenience and efficiency, Increased productivity/performance, the need to focus on core activities, Improvement of service delivery and quality, as well as to meet changing customers' needs, in the respective order. This result is however consistent with the work of Davis and Knox who found out that technical and business rationale are the reasons behind outsourcing in firms and organisations. 
Table 5: Rationale for Outsourcing in the Nigerian Banking Industry

\begin{tabular}{|l|ll|ll|}
\hline Variable & \multicolumn{2}{|l|}{ Applicable } & \multicolumn{2}{l|}{ Not Applicable } \\
& Freq & \% & Freq & \% \\
\hline The need to realize cost efficiency & 65 & $13.0 \%$ & 435 & $87.0 \%$ \\
Technical convenience and efficiency & 350 & $70.0 \%$ & 150 & $30.0 \%$ \\
Increase productivity/performance & 292 & $58.4 \%$ & 208 & $41.6 \%$ \\
The need to focus on core activities & 223 & $44.6 \%$ & 277 & $55.4 \%$ \\
Improvement of service delivery and quality & 208 & $41.6 \%$ & 292 & $58.4 \%$ \\
Gain access to new talent and technology & 26 & $5.2 \%$ & 474 & $94.8 \%$ \\
To prevent and reduce labour related issues & 27 & $5.4 \%$ & 473 & $94.6 \%$ \\
Government directive to downsize & 195 & $39.0 \%$ & 305 & $61.0 \%$ \\
Exhibition of professionalism & 13 & $2.6 \%$ & 487 & $97.4 \%$ \\
Provision of uninterrupted services & 102 & $20.4 \%$ & 398 & $79.6 \%$ \\
Easy availability of vendors with expertise and economies of & 5 & $1.0 \%$ & 495 & $99.0 \%$ \\
scale & & & & \\
To meet changing customers' needs & 207 & $41.4 \%$ & 293 & $58.6 \%$ \\
Promote efficiency in the use of labour, capital, information & 55 & $11.0 \%$ & 445 & $89.0 \%$ \\
technology and human resources & & & & \\
\hline
\end{tabular}

Source: Field Survey of Bank Workers in Lagos

\section{Benefits of Outsourcing Activities in the Nigerian Banks}

Outsourcing of banking activities is usually targeted at some benefits that will lead to increased productivity and bring about improved bank performance. In recent times, outsourcing as an evolving concept has been seen as a way for organisation to be more focused and be more productive. In corporate governance and banking industry, outsourcing has become more relevant such that managers now view their organisation operations as a value chain designed to provide value to the numerous clients. The managers determine what service or activity to be incorporated, outsourced, or joint ventured so that the bank can become efficient and more relevant to meeting the changing customers' needs and social challenges it is established to address. The activities that are integrated in the bank are the core competencies that are critical to the delivery of services to the clients.

These core activities thereby remain the focus of strategic attention and they are not considered for outsourcing or contracted out to a third party. The bank is a very sensitive establishment dealing with treasuries and valuables, and as such most of the bank activities are core and only a few non-core activities are outsourced. In view of the above analogy, there is need to measure the extent at which the outsourcing of the none-core activities has impacted on the overall performance, efficiency and productivity of the banking industry. Going by this, it is important to gauge the perceptions of bank staff, both management and non-management, on the benefits of outsourcing activities to the bank. The analysis of the responses obtained from the survey on the perceived benefits and risks of outsourcing activities is presented in table 6.

Table 6: The perceived benefits of outsourcing activities in Nigerian banks

\begin{tabular}{|l|l|l|l|l|l|}
\hline \multirow{2}{*}{} & Variable (Benefits) & \multicolumn{2}{l|}{ Applicable } & \multicolumn{2}{l|}{ Not Applicable } \\
\cline { 3 - 5 } & & Freq & $\mathbf{\%}$ & Freq & \% \\
\hline a & Reduces cost compared to in-house production & 51 & $10.2 \%$ & 449 & $89.8 \%$ \\
\hline b & Provides greater flexibility & 286 & $57.2 \%$ & 214 & $42.8 \%$ \\
\hline c & Reduces head counts/number of staff & 26 & $5.2 \%$ & 474 & $94.8 \%$ \\
\hline d & Enables bank to access new technology & 9 & $1.8 \%$ & 491 & $98.2 \%$ \\
\hline e & Reduces burden on managers & 109 & $21.8 \%$ & 391 & $78.2 \%$ \\
\hline f & Enables banks focus on core competencies & 21 & $4.2 \%$ & 479 & $95.8 \%$ \\
\hline g & enables bank to conserve resources for core projects & 13 & $2.6 \%$ & 487 & $97.4 \%$ \\
\hline h & Leads to improved services & 383 & $76.6 \%$ & 117 & $23.4 \%$ \\
\hline i & Helps to problem of managing industrial relations & 47 & $9.4 \%$ & 453 & $90.6 \%$ \\
\hline j & Helps to meet the set target & 193 & $38.6 \%$ & 307 & $61.4 \%$ \\
\hline k & Leads to growth of the bank & 408 & $81.6 \%$ & 92 & $18.4 \%$ \\
\hline
\end{tabular}

Source: Field Survey of Bank Workers in Lagos

From table 6 , the study revealed that out of the total 500 respondents examined, a remarkably larger proportion of the respondents, 408 or $81.6 \%$ approved that outsourcing leads to growth of the bank. A significant number, 383 or $76.6 \%$ of the respondents agreed that it leads to improved services, while 286 or $57.2 \%$ respondents indicated that it provides greater flexibility. A considerable number of the respondents, $193(38.6 \%)$ accepted that outsourcing helps to meet the set target, while 109 or $21.8 \%$ of the respondents suggested that it reduces burden 
on managers.

A lower proportion of $51(10.2 \%)$ respondents cited that outsourcing reduces cost compared to in-house production, 47 or $9.4 \%$ of the respondents say it helps to reduce the problem of managing industrial relations, 26 or $5.2 \%$ of the respondents complied that it reduces head count/number of staff, 21 or $4.2 \%$ of the respondents specified that it enables the bank to focus on its core activities/competencies, while 13 or $2.6 \%$ respondents cited that it reduces capital expenditure and enables bank to conserve resources for other projects, and the remaining few 9 or $1.8 \%$ of the respondents suggested that outsourcing enables bank to have a quick and reliable access to new technology. These lower responses only reflect the fact that the activities outsourced by the banks ate basically the non-core activities, and these may not have a direct bearing on the greater core services that are being carried out using the in-house staff. Hence, apart from the options enlisted as variables in the questionnaire, no other option was specified by the respondents.

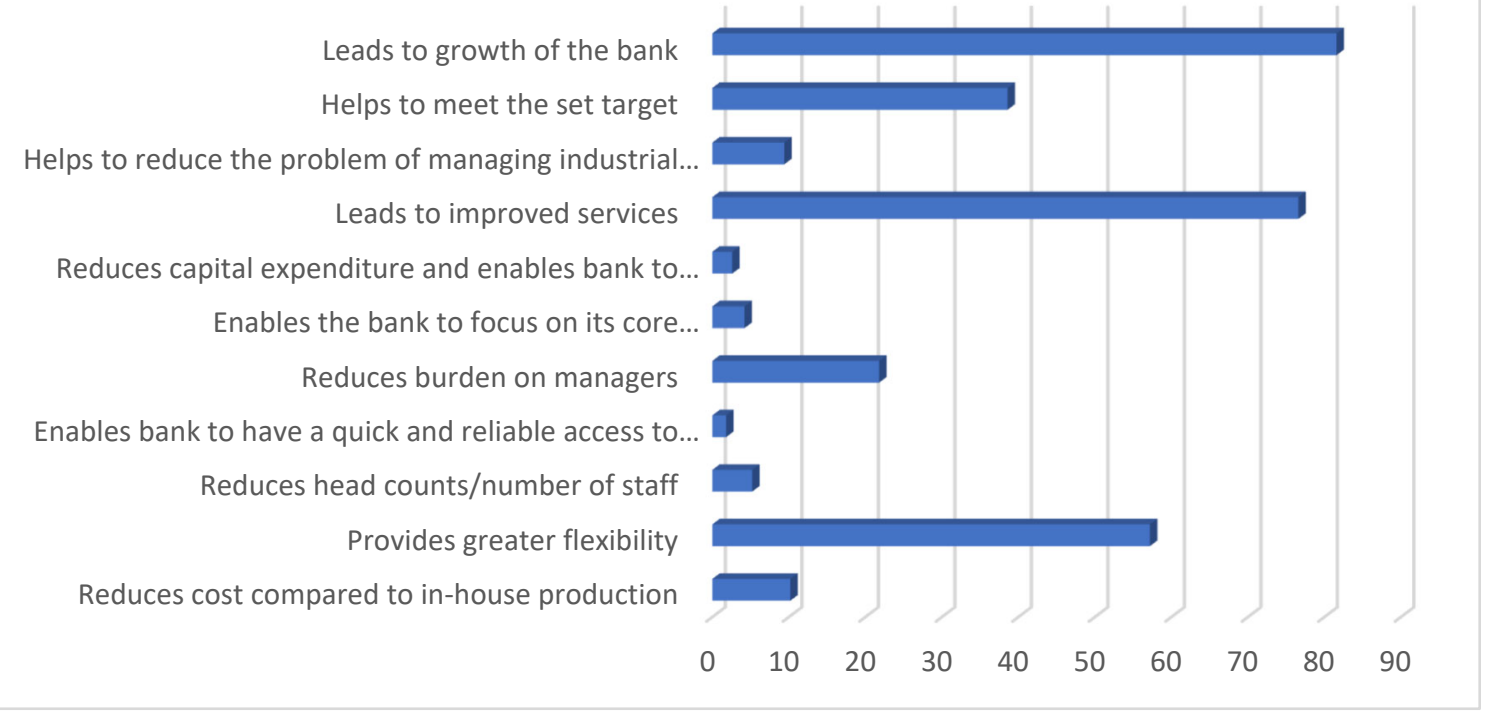

Figure 1: Benefits of Outsourcing to Banks in Nigeria

\section{The Perceived Risks of Outsourcing Activities in the Nigerian Banks}

The bank sector is a risk sensitive sector as most of their activities centre on economic treasuries which requires special attention and caution. There are certain factors that pose possible threats to outsourcing decision of banks. These factors surface as the negative impacts of outsourcing. This section examines those possible factors hindering outsourcing activities which are identified as the risks of outsourcing. The analysis of the responses generated from the field survey on the perceived risks of outsourcing activities in the Nigerian banks unfolds that, the most likely risk of outsourcing includes; inadequate expertise to oversee the service providers, poor suppliers' problem leading to additional cost, and that suppliers may damage the reputation of the bank/reputation risk.

\section{Table 7: The Perceived Risks of Outsourcing Activities in Nigerian Banks}

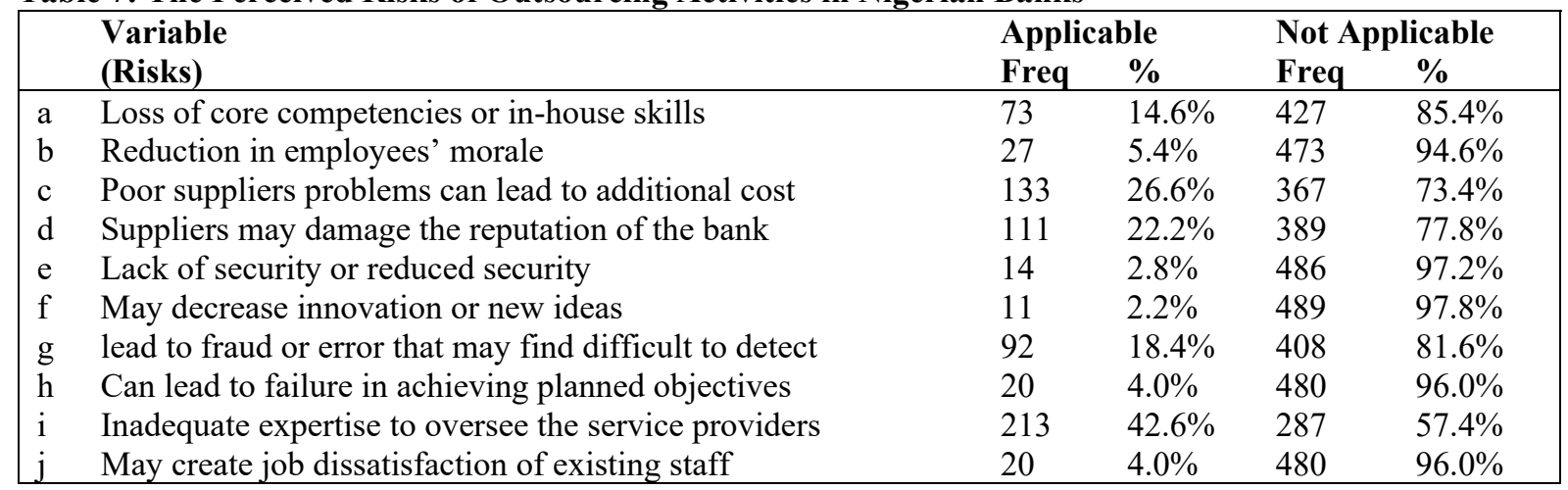

Source: Field Survey of Bank Workers in Lagos, 2014.

From table 7, the study established that $213(42.6 \%)$ of the total respondents identified the option "there could be inadequate expertise to oversee the service provider" as the most likely risk of outsourcing activities, 133 (26.6\%) of the respondents cited the option "poor suppliers problems can lead to additional cost" as the next perceived risk, while $111(22.2 \%)$ of the respondents indicated the option "suppliers may damage the reputation of the bank/reputation risk" as a perceived risk. A lower proportion of 92 or $18.4 \%$ respondents complied that, 
outsourcing may lead to fraud or error that the bank may find difficult to detect inspection, 73 or $14.6 \%$ of the respondents cited "loss of core competencies or in-house skills" as a likely risk, while 27 or $5.4 \%$ respondents chose the option "reduction in employees' morale". A very low proportion of the respondents with $20(4.0 \%)$ responses each suggested that it can lead to failure in achieving planned objectives, as well as create job dissatisfaction of existing staff. The option "lack of security or reduced security" had $14(2.8 \%)$ supporting responses, while others (yet unspecified) had no responses. Though, the result generated from the survey shows that, all the options provided in the questionnaire to measure the perceived risks of outsourcing had responses below average. However, it can still be established that the three most likely risks confronting outsourcing activities are:

(i) Inadequate expertise to oversee the service providers

(ii) Poor suppliers problems leading to additional cost, and that

(iii) Suppliers may damage the reputation of the bank/reputation risk

\subsection{Conclusion and Policy Implication}

This study examined the services outsourced in the Nigerian banking industry and analyzed the perceived benefits and risks of outsourcing activities of banks in Nigeria. Based on the data collected analyzed the paper established that on the average $(75 \%)$ of staff in the Nigerian banking industry were currently outsourced and at least one service in Bank operation, Administration, Marketing and Sales, Human Resources and IT was outsourced either partially or fully. Specifically, Security Cleaning, Recruitment and Training, ATM and I.T units and Marketing and promotion were identified by the respondents as the most outsourced activities by the banks. The study also found that the benefits that had resulted from outsourcing in the banks included improvement in service delivery, improved efficiency, meeting the set target, effective decision making, growth of the banks, increased customer base, freeing up resources to other areas, helped to avoid union challenges, helped to increase expertise and professionalism and led to better administration. Also, functional flexibility of the banks made deployment of individual workers to particular tasks more adaptable by implementing workplace practices such as multi-skilling teams or job rotation

The major risks associated with outsourcing in the banking industry as identified by the bankers and other stakeholders are: inadequate expertise to oversee the service providers, poor supplier's problems leading to additional cost, and supplier's failure may damage the reputation of the bank. Other challenges facing outsourcing were 'failure to adhere to quality requirement and specification, 'increased in the cost of outsourcing administration and provisions' and 'dilution of control'. The study also revealed that the challenges facing outsourcing in Nigerian banking industry included financial risk, lack of compliance with the contract, opposition from internal staff, failure to adhere to quality system, poor structure to manage outsourced functions well, dilution of control, poor planning and increase in the cost of administering the outsourcing function.

The implication of the findings is that Outsourcing is an emerging process in the Nigerian banking industry. Therefore, Nigerian banking industry needs to pass through a learning phase before outsourcing is recognized as an efficient management and regulatory tool. Thus the banking industry needs time before the capacities of managers and providers are adequately developed and streamlined.Outsourcing is complex and cannot be the solutions for all problems of the banking, services, not everything can or should be outsourced. When outsourcing is applied judiciously, it could contribute to the improvement of the bank services.

It is also vital for the continued success of the banks and its services to regularly review and update its outsourcing process. The management team should be actively involved in the supplier selection and management of the suppliers.

Therefore, outsourcing should be part of the overall strategy of the organization. Effective management of outsourcing relationship is an organizational imperative. There is the need for a formal policy on outsourcing. In most cases, the banks were able to articulate the types of activities that were outsourced or could be outsourced and the reasons for outsourcing their activities but these had not been formalized. It is very important for the Nigerian banking industry to have a dedicated outsourcing unit for ensuring that the organizations' outsourcing policy is applied consistently.

The banking sector is a very complex and delicate industry in which any error in its operation can have negative consequence on the overall economy. Therefore, outsouricng should be adopted with caution and only where necessary and inevitable. Bank operators must identify those activities that are core activities and those that are non-core activities and only those that are critical to the organisation success should not be outsourced. They should be performed internally and develop professionals to handle them. The non-critical activities that organization has no capacity to provide should be outsourced outrightly. Such activities include security office maintenance, advert and promotion, recruitment of staff and marketing. It was also observed that outsourcing was complex. Thus it cannot be the solution to all problems of the bank. The study concluded that Nigerian banks' engagement in outsourcing activiteis had contributed significnatly to their overall perforamnce of banks in Nigeria. 


\section{References}

Akinola, S.O. \& Longe, O.B. (unknown date), "Information Systems Outsourcing in Nigerian Business Organizations: Trends, Perceptions \& Effectiveness", Curtin University of Technology Perth WA

Alexander, M. and Young, D. (1996), "Strategic outsourcing”, Long Range Planning, Vol. 29 No. 1, pp. 116-9

Ang, S. and Cummings, L. (1997), Strategic Response to Institutional Influences on Information Systems Outsourcing. Organization Science, Vol. 8, pp. 235-255.

Arnold, U. (2000), "New Dimensions of Outsourcing: a combination of transaction cost economics and the core competences concept'”, European Journal of Purchasing and Supply Management, vol 6 No 1 pp 23-9.

Atkinson, J. (1984) Manpower strategies for flexible organisations. Available at: https://www.stonebridge.uk.com/uploads/courses/566.pdf (Accessed: 31 March 2016).

Aubert, B.A.; Patry, M. and Rivard, S. (1998), Managing the risk of IT outsourcing. Proceedings of the 32nd Hawaii International Conference on System sciences.

Avery G. (2000): Outsourcing Public health laboratory services: a blueprint for determining whether to privatize and how" public administration review, vol 60. No 4 pp. 330-7

Basel Committee (2004). Outsourcing in Financial Services. Bank for International Settlements, Basel Committee on Banking Supervision, Availableonline: http://www.bis.org/publ/joint12.htm

Beaumont, N. (2006) "Service Level Agreements: An Essential Aspect of Outsourcing" Services Industries Journal, 26 (4): 381-395.

Bers J.S. (1992): “Outsourcing; a deal or dilemma for FMs?; Facilities Design and Management” vol 11 No 3 pp. 54-7

Brandes, H., Lilliecreutz, J. and Brege, S. (1997), “Outsourcing - success or failure?”, European Journal of Purchasing \& Supply Management, Vol. 3 No. 2, pp. 63-75

Davis, P. R. and Knox, I. A. (unknown date). "The Reasons Why Organisations Outsource Information Technology Systems

Deakins, D., Logan, D., \& Steele, L. (2000), The Financial Management of the Small Enterprise. ACCA Research Report No. 64. London: The Association of Challered Certified Accountants, Certified Accountants Educational Trust.

DiRomualdo, A. and Gurbaxani, V. (1998) Strategic intent for IT outsourcing. Sloan Management Review, Summer, Volume 39, Issue 4, pp 67-80.

Duran, I. and Duran D. (2009), "Outsourcing-a way to maximize profit”. Annals Economic Science Series,74954.

Domberger S and Ternandez P. (1999), Public - private partnerships for service delivery" Business Strategy Review, Vol 10 No 4 pp. 29-39.

Espino-Rodriguez, T. F., \& Padron-Robaina, V. (2006). Outsourcing and its impact on operational objectives and performance: a study of hotels In the Canary Islands. Hospitality Management, 23(287-306),

Federal Reserve Bank of San Francisco (2004). Economic letter: outsourcing by financial services firms: The supervisory response. Available online www.frbsf.org/publications/ economics/ letter/ 2004/ e/2004-34.htrnl - 34k.

Glenn D. Israel (2012) "Determining Sample Size" A Publication series of the Agricultural Education and Communication Department, Florida Cooperative Extension Service, Institute of Food and Agricultural Sciences, University of Florida.

Green-Armytage, J. \& Hawkins S., 1998, 'Best Practice in Outsourcing End User Computing in Europe', Gartner Group 1998 Strategic Analysis Report Strategic Analysis Report, 8 December 1998.

Irefin, F.A., Olateju, O.I. \& Hammed, E.O. (2012) “Effect of Outsourcing Strategy on Project," Transitional Journal of Science and Technology, 1 (6): 128 - 143.

Harler, C. (2000), "Opting for outsourcing”, Business Communications Review, Vol. 30 No. 7, pp. 56-61

Huber, R. L., 1993, 'How Continental Bank Outsourced It's Crown Jewels', Harvard Business Review, January February 1993, pp.121-129.

Inegbedion, H. (2016), “Outsourcing of Human Resources Functions and Organizational Competitiveness in Nigeria, Sokoto Journal of the Social Sciences Vol. 6: No.1, pg. 122-136

Jegede, C.T. (2015). "A Study of Outsourcing and Performance of Commercial Banks in Lagos, Lagos State, Nigeria', Journal for Studies in Management and Planning, vol 1, pg. 598-606

Kakabadse, A and Kakabadse, N.C (2000a), "Sourcing: new face to economies of scale and the emergence of new organizational forms", Knowledge and process Management, vol. 7 No 2, pp. 107-18.

Kakabadse, N and Kakabadse, A.C (2000b): "Critical review outsourcing; a paradigm shift? The Journal of Management Development, vol. 19 No.8, pp. 670-728

Lacity. M., C. \& Hirschheim, R., (1995), Beyond the Information Systems Outsourcing Bandwagon - The Insourcing Response, J Wiley \& Sons, New York.

Lacity, M. and Willcocks, L. (1995). An Empirical investigation of information technology sourcing practices: 
Lessons from experience. MIS Quarterly, Vol. 22, pp. 363-408.

McFarlan, W. E., \& Nolan, R. L., (1995), 'How to Manage an IT Outsourcing Alliance', Sloan Management Review, vol.36, no.2, Winter 1995, pp. 9-23.

McIvor, R. (2008) What is the right outsourcing strategy for your process? European Management Journal, Volume 26, Issue 1, pp 24-34.

Nairametrics (2018), " $42 \%$ of Bank Employees Now Contract Staff as Fresh Graduate settle for Less". https://nairametrics.com

Ngwenyama, O.K and Boyson, N. (1999): "Marking the information systems outsourcing decision: a transaction cost approach to analyzing outsourcing decision problems", European Journal of Operational Research, vol. 115 No 2, pp. 351-67

Price Waterhouse Coopers (1999): “Global Top Decision Makers' Study on Business Process Outsourcing”. Price Waterhouse Coopers, Yankelovic Partners, Goldstain Consulting Group, New York, NY.

Quinn, J.B. (1999), "Strategic outsourcing: leveraging knowledge capabilities", Sloan Management Review, Vol. 40 No. 4, pp. 9-21.

Sameen S. Tayyeb I kn \& Belgaeem S. (2006); Contracting but not without caution: experience with outsourcing of health services in counties of the Eastern Mediterranean Region

Smith, M.A., Mitra, S. \& Narasimhan, S., 1998, 'Information Systems Outsourcing: A Study of pre-event Firm Characteristics', Journal of Management Information Systems, Fall 1998, vol.15, No.2, pp. 61-93.

The Outsourcing Institute (2000), Pages and articles from http://www.outsourcing.com/

The Outsourcing Institute (2006); Executive Survey: The Outsourcing Institute is Annual Survey of Outsourcing End Users.

Wasner, R (1999), “The Outsourcing Process - Strategic and Operational Realities,” Linkoping: EkonomiTryckarna AB, PG. 198

Williamson O.E (1985): The Economic institutions of capitation. The Tree Press New York.

Willcocks, L. P., Lacity, M.C., \& Feeny, D.F., 1995, 'IT Outsourcing: Maximize Flexibility and Control', Harvard Business Review, May - June 1995, pp.84-93.

Young (2003); Outsourcing and Benchmarking in a rural hospital; does economic theory provide the complete answer? http://rrhq.deakin:edu. 